\title{
It is time to put hurricane preparedness on the radar for individuals living with spinal cord injury
}

\author{
Lauren T. Shapiro $\mathbb{B}^{1} \cdot$ David R. Gater Jr. $\mathbb{D}^{2} \cdot$ James M. Shultz
}

Received: 14 March 2020 / Revised: 14 April 2020 / Accepted: 15 April 2020

(c) International Spinal Cord Society 2020

\begin{abstract}
Hurricane Dorian's devastating trajectory over the Northwest Bahamas was the most recent Atlantic storm to call attention to the catastrophic impact of climate change. Although disasters create adversities for all members of the affected population, people with disabilities and special medical needs are disproportionately challenged by such events and are more vulnerable to the conditions they create. This point-counterpoint series highlights the hardships faced by individuals living with spinal cord injury (SCI) when disasters strike. This commentary focuses on the time-urgent need to improve storm readiness among at-risk individuals living with SCI before the start of the upcoming hurricane season. We review the evidence indicating that tropical cyclones are becoming increasingly destructive in the era of climate change and consider how this trend may magnify the difficulties that those with SCI may experience before, during, and in the aftermath of a hurricane. We then review the ways in which health professionals caring for individuals with SCI can help them better prepare for hurricanes while also enhancing their own readiness to provide care during and after an extreme storm.
\end{abstract}

\section{Introduction}

The 2020 Atlantic hurricane season will soon be upon us. The aftermath of recent major storms is still being felt, perhaps no more so than by the survivors of Hurricane Dorian in the Bahamas [1,2]. Dorian was the fifth Category 5 Atlantic hurricane to make landfall since 2016. Its protracted passage over the Northwest Bahamas underscored two very dangerous trends: (1) hurricanes are becoming increasingly hazardous and (2) hardships associated with

$\triangle$ Lauren T. Shapiro

1xs973@med.miami.edu

1 Department of Physical Medicine \& Rehabilitation, University of Miami Leonard M. Miller School of Medicine, 1120 NW 14th Street, CRC 936, Miami, FL 33136, USA

2 Department of Physical Medicine \& Rehabilitation, Medical Director of Rehabilitation, Jackson Memorial Hospital, CoDirector, NIDILRR South Florida Spinal Cord Injury Model System, University of Miami Leonard M. Miller School of Medicine, 1120 NW 14th Street, CRC 958I, Miami, FL 33136, USA

3 Department of Public Health Sciences, University of Miami Leonard M. Miller School of Medicine, 1120 NW 14th Street, CRC 926, Miami, FL 33136, USA these storms are disproportionately challenging for those with chronic medical problems [1,2]. These observations have important implications for safeguarding individuals with disabilities and special medical needs residing in coastal or island communities, especially those living with spinal cord injury (SCI) [3].

\section{Climate change is changing Atlantic hurricanes}

Atmospheric scientists have carefully examined the evidence that shows how "climate drivers" such as uncharacteristically warm ocean waters, extending far down below the surface, and warm air temperatures that allow the atmosphere to hold more moisture, are altering how Atlantic hurricanes behave [4, 5]. Collectively, these storms are becoming stronger, in terms of higher peak wind speeds and rapid intensification, and wetter, in terms of increased precipitation rates and rainfall totals [4-6]. Moreover, the forward motion "translational" speed of some storms slows to near standstill above populated areas, adding to the devastation and trauma experienced by the affected communities [6, 7]. As a memorable example, after making landfall in 2017, Hurricane Harvey hovered over the warm waters of the Gulf of Mexico for 4 days, 
producing trains of rain bands that deluged the Houston area [8]. An examination of the environmental justice implications of Hurricane Harvey found that flooding was considerably worse in areas with a greater proportion of residents with disabilities [9].

\section{Hurricane preparedness and response considerations for persons living with spinal cord injury}

Now is the time for individuals living with SCI who reside in areas prone to tropical cyclone activity to educate themselves about their risks and preemptively take protective actions. Because individuals with SCI face unique challenges in the aftermath of major hurricanes, evacuation in advance of a storm may be considered. However, individuals with disabilities are less likely to evacuate in a disaster [10]. Persons with SCI may have limited options for transportation and sheltering. Indeed, the lack of accessible transportation was cited as a major factor impeding disabled individuals from evacuating their homes during Hurricane Katrina, resulting in at least one death of an individual with tetraplegia [11]. Personnel staffing medical shelters may lack the expertise to meet the care needs of this population. The need for an accessible environment may preclude an alternative option of being able to ride out a storm in the home of friends or family members who live outside the hurricane impact zone. In addition, some persons with SCI require equipment for life or function that may be difficult to transport, such as respiratory equipment and mechanical lifts. As such, individuals living with SCI must weigh the difficulties involved in evacuating one's home and community against the considerable risks of remaining in an area where a major hurricane is predicted to strike.

Studies have shown that individuals with disabilities, including those with SCI, are inadequately prepared for disasters. People with disabilities are significantly less likely to state that they are prepared for an emergency, to have an adequate supply of water, or to have a working flashlight [12]. In a study of full-time wheelchair users with SCI, although many had developed plans for evacuating from their homes and workplaces, relatively few had plans for evacuating from their towns [13]. Detailed evaluation of their evacuation plans found that many were lacking critical components, including making arrangements for postevacuation transportation and stockpiling sufficient supplies [14].

Postimpact, individuals with SCI who remain in hurricane-affected areas will suffer more than most. They may confront physical, emotional, and financial stressors as they attempt to fulfill their care needs. We have previously written about the hardships faced by this population [3] and we highlight the most pressing concerns in Table 1.

\section{Physicians and health professionals play critical roles in preparing persons living with $\mathrm{SCl}$ for climate-driven hurricanes}

It is crucial for members of health care teams who provide care for individuals with SCI to proactively engage in personal, client, and community hurricane preparedness.

\section{Personal preparedness}

Health care providers who live and/or work along the Atlantic coast or reside in island states must first take actions to ensure their own readiness for hurricane season. Obtaining emergency supplies in advance precludes the need to engage in frenzied shopping in crowded stores when a hurricane is looming on the horizon. Health professionals who reside on barrier islands or along coastal evacuation zones should plan carefully to move their families to a predetermined safe location where they can shelter during a storm. Thoughtful planning should facilitate a rapid return to providing patient care following the event. Health professionals should plan for the contingency that they may be displaced from their home communities for a period of time and they will need to ensure seamless coverage for their clinical responsibilities.

Health care providers responsible for providing inpatient care to individuals with SCI during a hurricane should make appropriate plans for the care and safety of their families, including children, pets, and other dependent persons in the household. They should devise a family communication and reunification strategy in case a family member becomes unexpectedly separated or is missing.

\section{Client preparedness}

Health care professionals must ensure that persons to whom they provide care are well-prepared for a range of emergency and disaster scenarios, including hurricanes. Disaster readiness for those with SCI should include developing a local personal support network of people who are willing and able to help the individual in an emergency. Individuals with SCI should receive training, including active rehearsal, so they are prepared to verbally direct an untrained caregiver to assist them in meeting their needs. Persons with SCI should also be encouraged to develop a comprehensive evacuation strategy that includes detailed transportation plans and a known, and agreed upon, family meeting place. They should be educated about the need to register for evacuation assistance with their local governmental agencies in advance of a storm. Each person with SCI needs to acquire, maintain, and replenish a 7-day supply of essentials -at a minimum-including food, water, catheters, and medications [3]. 
Table 1 Ways in which hurricanes may impact individuals with SCI.

Power outages

Flooding and debris

Care disruption

Access to medications and supplies

Property damage

Displacement from home

Psychological trauma
- Inability to power necessary respiratory equipment, such as ventilators, can acutely threaten survival.

- Inability to charge power chairs impedes mobility.

- Inoperable elevators may leave people trapped in high-rise buildings.

- Lack of temperature control may result in moisture-related skin damage and puts those with impaired thermoregulation at risk for heat and cold-related illnesses.

- Poor visibility in low light conditions complicates wheelchair navigation, safe administration of medications, and the performance of bladder and bowel programs.

- Pose risk for drowning and injuries.

- May result in damage or loss of homes, vehicles, and equipment.

- Complicates wheelchair propulsion/navigation.

- Those who depend on home health services may have difficulty getting care needs met.

- Hospital and clinic closures may result in delays obtaining necessary medical care for storm-related and chronic conditions, as well as assistance with replacement of needed supplies, medications, and equipment.

- Inability to obtain medications, such as baclofen and benzodiazepines, may result in risk for dangerous withdrawal syndromes.

- Lack of needed supplies for bladder and bowel programs may result in autonomic dysreflexia.

- Damage to one's home may result in financial stresses, the need for displacement, mold-related illness, and/or impede function within the home environment.

- Vehicular damage may impede one's ability to obtain necessary supplies, leave the affected area, and/or seek medical attention.

- Individuals may need to remain in homes or facilities that are less accessible to them, thereby impeding their function.

- Patients may be far from their usual sources of medical care, complicating appropriate follow-up, the provision of home health and rehabilitative services, and the refilling of medications (including intrathecal baclofen pumps).

- There may be barriers to returning home poststorm, including gasoline shortages and lack of accessible transportation options.

- Individuals may experience losses and life changes which elevate risks for mood and/or anxiety disorders.

- Exposure to hurricane hazards increases the risk for post-traumatic stress disorder [15].
Health care providers should also prepare individuals with SCI for the likelihood of widespread and prolonged power outages. Physicians should complete certificates with utility companies for priority turn-on service for all people with SCI, especially those who rely on electricity for life or function. Clinicians should also ensure that generators, mechanical in/exsufflators, and bag-mask equipment are available to all ventilator-dependent persons. Justification of medical necessity may be required and is certainly warranted. Escape chairs should be ordered for those who live or work in high-rise buildings to enable evacuation in the event of loss of power to elevators. Education should be provided to those with impaired thermoregulation regarding methods of heating and cooling during an emergency.

\section{Providing care to people with $\mathrm{SCl}$ in the aftermath}

Health care providers should help coordinate and/or provide prompt care for individuals with SCI who experience stormrelated illnesses or injuries. Providers should assist those needing repairs or replacements for damaged or lost equipment and be available for ordering necessary supplies and medications, which similarly may be lost or damaged [3]. Health care professionals should provide orders for individuals with SCI to resume home health or outpatient therapies, with minimal interruption, as soon as these services are once again available in the community. They should assess for psychological distress and refer to mental health professionals when needed [15]. It should be noted that health care providers outside the zone of impact may be called upon to assist persons with SCI who are displaced from their home communities. Providers who manage intrathecal baclofen pumps may be needed to provide pump refills to displaced patients so as to avoid baclofen withdrawal. Oral baclofen should also be prescribed and made available in advance to prevent withdrawal.

\section{Consultation to community leadership}

SCI physicians can share their contact information and expertise with public health and emergency management partners and educate them on how to best protect and maintain care for people with SCI during hurricane season [16, 17]. 


\section{Potential impact of the coronavirus disease 2019 (COVID-19) pandemic}

In the absence of a vaccine or widespread acquired immunity, the ongoing, escalating COVID-19 pandemic carries important implications for preparedness for the 2020 hurricane season. On April 2, 2020, Colorado State University's Tropical Meteorology Project issued its annual forecast, predicting above average numbers of named storms (16), hurricanes (8), and major hurricanes (4) [18].

The near-singular focus on COVID-19 is likely to diminish the attention paid to preparing for the approaching storm season. Widespread cancellations of physician and therapy clinic visits in recent weeks may also result in missed opportunities for health care professionals to address disaster readiness for people with SCI. Many individuals in the community, including those living with SCI, have stockpiled food and supplies as they physically separate and self-isolate. This is one dimension of hurricane preparedness that may be ahead of schedule, though such stockpiles may dwindle as the pandemic lingers.

Beyond the shared risks that would be experienced by all citizens, a major hurricane strike in the midst of the pandemic would be especially catastrophic for those living with SCI. The need for social distancing may further limit their options for transportation and evacuation in advance of an impending storm. Crowded medical and/or special needs shelters are conducive to viral transmission among vulnerable persons. Moreover, an already-strained health care system and workforce may be left unable to provide necessary care for storm-related illnesses and injuries.

\section{Concluding comments}

Individuals with SCI living in at-risk areas should immediately commence their preparedness activities in advance of the impending hurricane season. Warming temperatures have contributed to altered hurricane properties, resulting in greater destructive forces, as well as considerable harm to affected populations, especially those with chronic medical conditions. Health care professionals must work to enhance the level of hurricane readiness among people with SCI. They should collaborate with emergency management officials in planning for the needs of this population in the event of a major hurricane and assist in ensuring their needs are met in the aftermath of such disasters.

\section{Compliance with ethical standards}

Conflict of interest The authors declare that they have no conflict of interest.
Publisher's note Springer Nature remains neutral with regard to jurisdictional claims in published maps and institutional affiliations.

\section{References}

1. Shultz JM, Sands DE, Kossin JP, Galea S. Double environmental injustice-climate change, Hurricane Dorian, and the Bahamas. N Engl J Med. 2020;382:1-3. https://doi.org/10.1056/NEJMp1912965.

2. Greig E, Green BA, Ford H, Bertrand Farmer D, Nottage KM, Espinel Z, et al. Extreme population exposure: Hurricane Dorian medical response in Great Abaco, Bahamas. EClinicalMedicine. 2020;100274. https://doi.org/10.1016/j.eclinm.2020.100274.

3. Shapiro LT, Gater DR, Espinel Z, Kossin JP, Galea S, Shultz JM. Preparing individuals with spinal cord injury for extreme storms in the era of climate change. EClinicalMedicine. 2020;100232. https://doi.org/10.1016/j.eclinm.2019.12.002.

4. Knutson T, Camargo SJ, Chan JC, Emanuel K, Ho C, Kossin J, et al. Tropical cyclones and climate change assessment: Part I: detection and attribution. Bull Am Meteorol Soc. 2019;100:1987-2007. https://doi.org/10.1175/BAMS-D-18-0189.1.

5. Knutson T, Camargo SJ, Chan JC, Emanuel K, Ho C.Kossin J, et al. Tropical cyclones and climate change assessment: Part II: projected response to anthropogenic warming. Bull Am Meteorol Soc. 2020, in press. https://doi.org/10.1175/BAMS-D-18-0194.1.

6. Hall TM, Kossin JP. Hurricane stalling along the North American coast and implications for rainfall. npj Clim Atmos Sci. 2019;2:17 https://doi.org/10.1038/s41612-019-0074-8.

7. Kossin JP. A global slowdown of tropical-cyclone translation speed. Nature. 2018;558:104-7. https://doi.org/10.1038/s41586018-0158-3.

8. Risser MD, Wehner MF. Attributable human-induced changes in the likelihood and magnitude of the observed extreme precipitation during Hurricane Harvey. Geophys Res Lett. 2017;44:12457-64. https://doi.org/10.1002/2017GL075888.

9. Chakraborty J, Collins TW, Grineski SE. Exploring the environmental justice implications of Hurricane Harvey flooding in Greater Houston, Texas. Am J Public Health. 2019;109:244-50. https://doi.org/10.2105/AJPH.2018.304846.

10. Mace SE, Doyle CJ, Askew K, Bradin S, Baker M, Joseph MM, et al. Planning considerations for persons with access and functional needs in a disaster-Part 2: evacuation and sheltering. Am J Disaster Med. 2018;13:195-206. https://doi.org/10.5055/ajdm. 2018.0300.

11. Frieden L, National Council on Disabilities. The impact of Hurricanes Katrina and Rita on people with disabilities: a look back and remaining challenges. 2006:1-26. https://ncd.gov/rawmedia repository/e89f084e_e132_496c_a5b8_56351dfb3f10.pdf. Accessed 3 March 2020.

12. Smith DL, Notaro SJ. Personal emergency preparedness for people with disabilities from the 2006-2007 Behavioral Risk Factor Surveillance System. Disabil Health J. 2009;2:86-94. https://doi.org/10.1016/j.dhjo.2009.01.001.

13. McClure LA, Boninger ML, Oyster ML, Roach MJ, Nagy J, Nemunaitis G. Emergency evacuation readiness of full-time wheelchair users with spinal cord injury. Arch Phys Med Rehabilit. 2011;92:491-8. https://doi.org/10.1016/j.apmr.2010.08.030.

14. Hogaboom NS, Oyster ML, Riggins MS, Boninger ML. Evacuation preparedness in full-time wheelchair users with spinal cord injury. J Spinal Cord Med. 2013;36:290-5. https://doi.org/ 10.1179/2045772312Y.0000000050.

15. Espinel Z, Kossin JP, Galea S, Richardson AS, Shultz JM. Forecast: increasing mental health consequences from Atlantic hurricanes throughout the $21 \mathrm{st}$ century. Psychiatr Serv. 2019;70:1165-7. https://doi.org/10.1176/appi.ps.201900273. 
16. Burns AS, O'Connell C, Rathore FA. Meeting the challenges of spinal cord care following sudden onset disaster-lessons learned. J Rehabilit Med. 2012;44:414-20.

17. Mills JA, Durham J, Packirisamy V. Rehabilitation services in disaster response. Bull World Health Organ. 2017;95:162-4.
18. Klotzbach PJ, Bell MM, Jones J. Extended range forecast of atlantic seasonal hurricane activity and landfall strike probability for 2020. Colorado State University, Department of Atmospheric Science; 2020. https://tropical.colostate.edu/media/sites/111/2020/ 04/2020-04.pdf. 